\title{
Assessment of Students' Knowledge of Computer: Construction of a Test for Assessment
}

\author{
Shamsa Aziz and Hamid Hassan
}

\begin{abstract}
To assess students' knowledge about computers and to explore the factors affecting the computers' knowledge a test was constructed, validated and pilot tested. Item analysis was carried out by calculating Difficulty Index and Discrimination Power. Revised version of the test was administered on 1068 students of ICS. Findings showed that gender, personal computers, physical facilities and teachers' qualification effect students' knowledge. It is recommended that better physical facilities and well trained teachers may be provided in the colleges.
\end{abstract}

Index Terms-Computer science, students knowledge about computers, assessment.

\section{INTRODUCTION}

With the growth in knowledge human society has evolved into a more coordinated and organized shape and systems of formal education came into existence. Mankind struggled to facilitate human life and a branch of knowledge called Technology came into existence. Knowledge is produced by men in the shape of theories and application of these theories emerges in the form of technology which reshaped and restructured the human societies. Technology has become a powerful change agent in human society. It appears that future will witness a time when an increasing percentage of workers will be processing and transmitting information. The students who are familiar with the use of computers will have a great advantage in the job market over students who lack such knowledge/training The knowledge of computers will be an asset in an ever more competitive employment market. The immense educational potential of information technology also means that all students would need it to play a central role in their future careers

As computer applications continue to grow in every day life, instructions about computer are also growing. In Pakistan computer instruction is being emphasized at intermediate level and is expanding rapidly. The importance of computer education and the belief that the future success of our nation largely depends upon the availability of excellent computer personnel is undoubtful. It is necessary to establish a well-educated and adequately prepared society to exploit the benefits of computers and to control their use when necessary.

A subject of computer science is being offered at secondary (Grade IX-X) and higher secondary (Grade

Manuscript received September 20, 2013; revised November 21, 2013.

Shamsa Aziz is with the Department of Education, International Islamic University Islamabad, Pakistan (e-mail: phd_edu@yahoo.com).

Hamid Hassan is with the Federal College of Education, Islamabad, Pakistan (e-mail: phd_edu@hotmail.com).
XI-XII) level in the scheme of studies of different Boards of Intermediate and Secondary Education in the province of Punjab since 1990. However, Punjab Information Technology Board (PITB) was established in 1999 for the development, administration and promotion of the information technology. In the year 2000 PITB was given the mandate of starting Intermediate in computer Science (I.C.S.) program in government colleges in collaboration with the private sector The curricula of computer science for intermediate have been revised time and again keeping in view the emergence of several new dimensions in the field.

There is a need to assess the knowledge gained by students of computer. In order to take remedial measures, to overcome flaws in the curriculum and to arrange such conditions that can fulfill the future needs in the field of information technology.

Keeping in view these considerations researcher planned to construct a test to assess the knowledge of computers as effective use of computers require knowledge of computers, actual computer experience and continuous learning. The main objectives of the study were to:

- Develop a computer knowledge test

- Get it refined through its pilot testing, item analysis and validation

- Determine its reliability

- Determine its usability

- To study the effect of different demographic variables on students' knowledge of computers

Knowledge of Computers means the students' familiarity with basic components of a computer, computer capabilities and computer use in society, and the familiarity with programming languages and functions of computer applications.

Learning about computers is one of the major ways through which students acquire experience with new information technology. This is important because using computers and computer applications require a certain amount of basic knowledge and skills with regard to the functioning of computers and software packages.

Every one who is acquainted with computers and their applications for certain tasks knows that there is no end to what can be learned about computers. It is just like the field of medicine, where every one who wants to live healthy, does not need to become a doctor; for surviving with computers, one does not need to be a computer specialist.

Reference [1] views that students need to have certain generic knowledge (for example of hardware components and software packages) and should understand some basic principles of how to operate software packages and should understand some basic principles of how to operate computer 
equipment of different types, such as how to switch on a machine, how to start a program, how to store information, what is a mouse etc

\section{Procedure And Methodology}

The test construction for the assessment of students' knowledge of computer passed through the following phases.

- Item construction

- Validation

- Pilot testing

- Item analysis

- Validation of the final version of the test

- Reliability

\section{A. Item Construction}

A test comprising 88 multiple-choice items was prepared. Test items were not text based, as it was not an achievement test. While developing test items researcher kept in view the UNESCO guidelines for computer science curriculum. To give positive, practical help to all UNESCO countries, the International Federation for Information processing (IFIP) has specified a curriculum in informatics/ computer science According to IFIP different countries are at different phases of development in the use of information technology within government, commerce and wider society. Three distinct phases have been identified known as

- Information Phase

- Communication Phase

- Automation phase

The conditions prevailing under each phase has been explained and Pakistan at present is in Information Phase and entering into the communication phase because now the industries, banks and government offices are using computers as a tool. There is a tendency towards personal ownership of computers and computer networking.

Reference [1] is of the view that computer knowledge comprises of information related to hardware components, software packages, understanding operations of software packages and general awareness of internet. So the items construction was aimed to assess the information related to these concepts.

\section{B. Validation by Experts}

Three experts validated the test. Two were computer teachers of ICS, one from Government Girls Higher Secondary School Committee Chowk Rawalpindi and the other from Government College for Boys Satellite Town Rawalpindi. The third expert was a MCS graduate. The experts were provided with the copies of the test and asked to comment on its readability, understandability, difficulty level and comprehensiveness. They were of the opinion that item number $1,2,5,13,1518,19,34,42,44,45,48$ and 78 were difficult. There was consensus among them that test was comprehensive but lengthy.

\section{Pilot Testing}

Test was administered to students at Government College for Boys Asghar Mall, Rawalpindi for pilot testing. The total number of students was 43 to whom test was administered.
Out of them 20 were from 1 st year and 23 were from 2 nd year. They were asked to complete the test in 90 minutes. Test was administered in actual classroom situation.

\section{Item Analysis}

On the basis of pilot test data, item analysis of the test was carried out. Item analysis passed through the following phases.

1) Scoring of the Test: Test of all the students were scored with the help of key for scoring. Scores were entered in a table in descending order.

2) Difficulty Index: Item difficulty for each item was calculated using the formula.

$$
P=\text { Number of students correct on the item }
$$

here

$$
\begin{gathered}
P=\text { Item difficulty for a particular item } \\
N=\text { Total number of students to whom the test was } \\
\text { administered } \\
\text { Value of } P \text { varies from } 0.0 \text { to } 1.0
\end{gathered}
$$

3) Discrimination Power: Discrimination Power of each item was computed in the following way

The test scores were arranged in descending order. Twenty five percent of the students were taken from the top and $25 \%$ were taken from the bottom. In this way, two groups were formed, one of top scorers and the other of bottom scorers. Each group consists of 11 members.

The discrimination power of each item was calculated using the following formula.

$$
D r=P T-P B
$$

here

$D r=$ the item discrimination power of a particular test item $P T=$ the proportion of students of top group who are correct on the item

$P B=$ the proportion of students of bottom group who are correct on the item

While

$P T=$ Number of people in the top group who are correct on the item

Number of students in the top group

$P B=$ Number of people in the bottom group who are correct on the item

Number of students in the bottom group

According to [2] and [3] items with discrimination index of 0.40 and above are very good ones, items with discrimination index of 0.30 to 0.39 are reasonably good but can be improved and items with discrimination index of 0.20 to 0.29 are marginal items and usually need improvement. Similarly, difficulty index of multiple-choice items having four distracters should be 0.375 to 0.625 .

Keeping in view the above-mentioned criteria, items having discrimination index less than 0.30 and having difficulty index below 0.20 (very difficult items) and above 0.80 (very easy items) were deleted. Final version of the test consisted of 50 items.

4) Alidation of the Final Version of the Test by experts

Same panel of experts validated the final version of the test who validated the 1 st version, and were of the opinion that test was comprehensive, readable and of moderate difficulty 
level.

5) Reliability

Reliability of the 1st and final version of the test was calculated through Kuder-Richardson formula $K 21$

$$
r=(K)(S D) 2-X(K-X)
$$

here

$$
(S D) 2(K-1)
$$

$r=$ reliability of total test

$K=$ the number of items in the test

$S D=$ the standard deviation of the scores

$X=$ the mean of the scores

Reliability for final versions of the test was 0.87 .

\section{EFFECT OF DEMOGRAPHIC VARIABLES ON KNOWLEDGE OF COMPUTERS}

To explore the effect of demographic variables a research was carried out on 1068 students of ICS (Intermediate in computer sciences) of randomly selected 15 colleges of the Punjab. Test was administered by formally trained representatives of the researcher in actual classroom setting. A group of six representatives were provided a comprehensive orientation regarding conduction of the knowledge test in a formal session. They were also provided with some written instructions. Students were briefed about the needs of the research; they were assured that their performance would not affect their regular evaluation. Information about students' gender, grade, personal computer and previous knowledge of computers was solicited through demographic sheet attached with the test. Data were analyzed using SPSS (Statistical Package for Social Sciences); Independent sample t test was used to test the following hypotheses.

$\mathrm{H}_{01}$ : There is no significant effect of gender on students' knowledge of computer

$\mathrm{H}_{02}$ : There is no significant effect of personal computer on students' knowledge of computer

$\mathrm{H}_{03}$ : There is no significant effect of physical facilities on students' knowledge of computer

ANOVA was used to test the following hypothesis.

$\mathrm{H}_{04}$ : There is no significant effect of teachers' qualification on students' knowledge of computer

\section{DATA ANALYSIS}

TABLE I: DIFFERENCE BETWEEN MALE \& FEMALE STUDENTS’ KNOWLEDGE OF COMPUTERS

\begin{tabular}{lccccc}
\hline Gender & $N$ & Mean & $t$. & $d f$ & Significance \\
\hline Male & 643 & 19.81 & 11.661 & 1066 & .000 \\
Female & 425 & 26.33 & & & \\
\hline
\end{tabular}

In Table I value (11.661) is significant at .05 level of significance, so the null hypothesis stating that there is no significant effect of gender on students' knowledge of computers is rejected and it is concluded that there is a significant effect of gender on students' knowledge of computers. Female students have higher mean score (26.33) than the male students (19.81) on knowledge test.

In Table II, value (3.807) is significant at .05 level of significance, so the null hypothesis that: there is no significant effect of personal computer on students' knowledge of computers is rejected and it is concluded that there is a significant effect of personal computers on students' knowledge of computer.

The students who have personal computer have higher mean score (24.16) than the students who have no personal computer (21.71) on knowledge test

TABLE II: DifFERENCE BETWEen PERSON Who OWN A PERSONAL COMPUTER AND WHO DOES NOT OWN PERSONAL COMPUTERS

\begin{tabular}{lccccc}
\hline $\begin{array}{l}\text { Personal } \\
\text { computer }\end{array}$ & $\mathrm{N}$ & Mean & $t$. & $d f$ & Significance \\
\hline $\begin{array}{l}\text { Personal } \\
\text { computer }\end{array}$ & 302 & 24.16 & 3.807 & 1066 & .000 \\
$\begin{array}{l}\text { No personal } \\
\text { computer }\end{array}$ & 766 & 21.71 & & & \\
\hline
\end{tabular}

TABLE III: DIFFERENCE BETWEEN THE STUDENT' KNOWLEDGE OF COMPUTERS HAVING SUFFICIENT PHYSICAL FACILITIES AND INSUFFICIENT PHYSICAL FACILITIES

\begin{tabular}{lccccc}
\hline $\begin{array}{l}\text { Physical } \\
\text { facilities } \\
\text { colleges }\end{array}$ & at & Mean & $t$. & $d f$ & Significance \\
\hline Sufficient & 251 & 25.71 & 6.812 & 459.35 & .000 \\
Insufficient & 817 & 21.39 & & & \\
\hline
\end{tabular}

In Table III, $t$ value (6.812) is significant at .05 level of significance, so the null hypothesis that: there is no significant effect of physical facilities on students' knowledge of computer is rejected and it is concluded that there is a significant effect of phyical facilities on students' knowledge of computers

The students who have sufficient physical facilities at colleges have higher mean score (25.71) than the students who have insufficient physical facilities (21.39) on knowledge test.

TABLE IV: DIFFERENCE IN STUDENTS’ KNOWLEDGE OF COMPUTERS DUE TO TEACHERS' QUALIFICATIONS

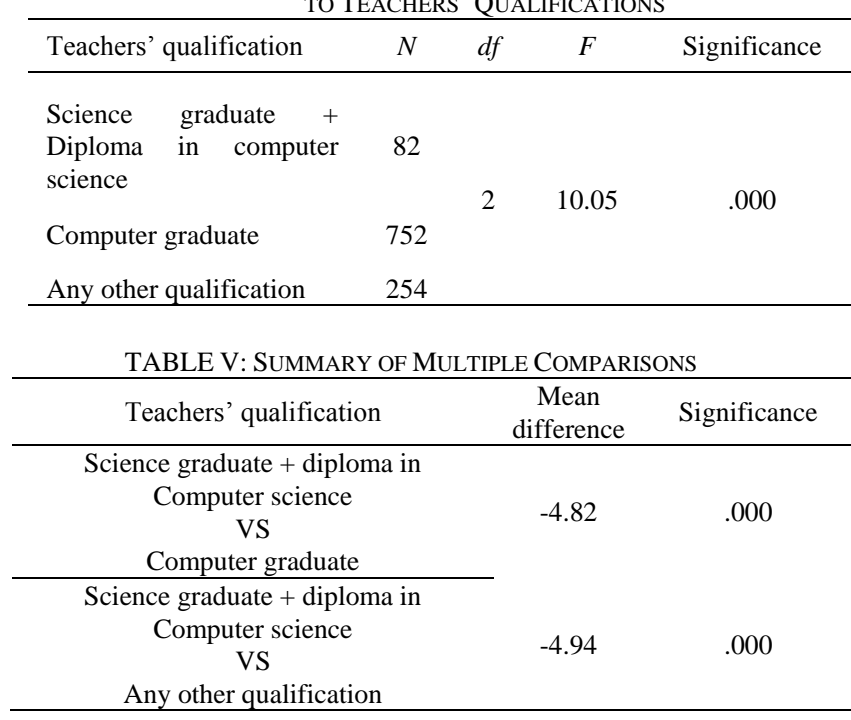

$F$ value (10.05) in Table IV is significant at .05 level of significance, so the null hypothesis that: there is no significant effect of teachers' qualification on students' knowledge of computer is rejected and it is concluded that 
there is a significant effect of teachers' qualification on students' knowledge of computers.

As the results are significant, it was decided to run LSD Post Hoc Test of Multiple Comparison. However only those significant mean differences are presented here which contribute the most in making the results significant.

As shown in table above the overall results for the post hoc test indicate that: the students' knowledge of computers is significantly affected by the teachers who are Science graduates + diploma in Computer studies and Computer graduates

\section{RESULTS AND DISCUSSION}

Gender, personal computer, physical facilities and teachers' qualifications all the demographic variables has affected the knowledge of computers. Different research studies have shown different findings [4]-[7]. Reference [8], [9] explored that gender had no effect on students' knowledge of computers. Reference [10]-[17] investigated that male students were better than females. While [18] showed that females were better than males. Reference [19] perceived that males show more favorable results towards computers because computers may be a career asset for them. There is a significant effect of personal computer on students' knowledge of computer; as personal computer reduces anxiety by providing excessive opportunity of working with computers hence results in better knowledge. Reference [1], [7] and [20] were also of the same view. Where as [15] concluded that personal computers had no effect on students' knowledge of computers

\section{RECOMMENDATIONS}

Colleges offering the subject of computer Sciences should provide sufficient physical facilities and trained teachers

Government may provide loan to the students on easy installments for buying personal computers

Gender disparities must be tried to minimized through a comprehensive complain through media and educational authorities

\section{REFERENCES}

[1] W. J. Pelgrum and T. Plomp. (2000). What do students Know, Learn and Think about Computers In IEA-Comped First Report Stage. [Online]. Available: http://www.mScp.Edte.untwent. ul/sitems1/extern/comped/fr2/chap4.htm

[2] R. L. Eble and D. A. Frisbie, Essentials of Education Measurement: Englewood Cliffs, New Jersy: Prentice Hall, Inc, 1986.

[3] R. M. Thorndike et al., Measurement and Evaluation in Psychology and Education, New York: Macmillan Publishing Co., 1991.

[4] D. Moe, The Effects of SEX, Residence Status, Grade Level, and Usage Level on Computer Equality, ERIC Document Reproduction Service No. ED 225 182, 1984.

[5] M. Linn, Fostering Equitable Consequences from Computer Learning Environments Sex Roles, vol. 3, pp. 229-240, 1985.

[6] M. J. Skulkhu, "Computer literacy levels and attitudes toward computers of Thai Public University students," Dissertation Abstracts International, 50-11A, 3497, 1989.

[7] M. Al-Badar, "Predictors of success in self -instruction courses on microcomputer application software," Dissertation Abstracts International, 5408A, 2991, 1993.
[8] L. J. Francis, "The Relationship Between Computer Related Attitudes and Gender Stereotyping of Computer Use," Computers and Education, vol. 22, no. 4, pp. 283-289, 1994.

[9] A. Morgan. Computer anxiety: A survey of computer training, experience, anxiety, and administrative support among teachers. [Online]. Available: http: www.biochem.OKState.edu/OAS/OJAS/amorg.htm

[10] T. Levin and C. Gordon, "Effects of Gender and Computer experience on Attitudes toward Computers," Journal of Educational Computing Research, vol. 5, no. 1, pp. 69-88, 1989.

[11] M. Igbaria and A. Chakrabarti, "Computer Anxiety and Attitudes towards Micro Computer Use," Behavior and Information Technology, vol. 9, pp. 229-241, 1999.

[12] K. Singh, Attitudes towards, Preference for, and Knowledge of Computers among Gifted and Average Junior High Children, (ERIC Document Reproduction Service No. ED 371 550, 1992.

[13] T. B. Barrier and T. M. Margonio, "Pretest-post test measures of introductory computer students' attitudes toward computers," Journal of Information System Education, vol. 5, no. 3, 1993.

[14] L. Shashani, "Gender-differences in Computer Experience and its Influence on Computer Attitudes," Educational Computing Research, vol.11, no. 4, pp. 347-367, 1994.

[15] L. Shashani, "Gender Differences in Computer Experiences and its Effect on Computer Attitudes," Psychological Abstracts, vol. 82, no. $12,1995$.

[16] F. C. Fletcher and T. Suddendorf, "Computer Attitudes, Gender and Exploratory Behavior: a developmental study," Journal of Educational Computing Research, vol. 15, no. 4, pp. 369-392, 1996.

[17] C. Comber et al., "The effects of age, gender, and computer experience upon computer attitudes," Educational Research, vol. 39, no. 2, pp. 123-133, 1997.

[18] O. Jegede, P. Okebukola, and G. Aiewole, Attitude to the use of the Computer for Learning Biological Concepts and Achievement of Students in an Environment Dominated by Indigenous Technology, (ERIC Document Reproduction Service), 1990.

[19] R. Anderson, Gender and Computers-The Present, 2002.

[20] A. M. Colley et al., "Effects of gender role identity and experience on computer attitude components," Journal of Educational Computing Research, vol. 10, no. 2, pp. 129-137, 1994.

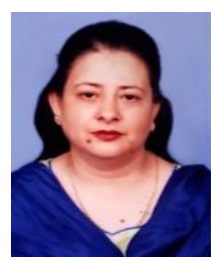

Shamsa Aziz was born in Lahore the Capital of Punjab on September 1, 1964. She completed her Ph.D. in education from the University of the Punjab, Lahore, Pakistan in 2004. Furthermore she also did her masters in political science and science education from the University of the Punjab, Lahore, Pakistan, in 1993 and 1988 respectively. She completed did her post doc. form the University of Glasgow, Glasgow, Scotland, UK under the guidance of professor Emeritus Norman Reid in 2013.

Currently, she is working as an assistant professor in one of the finest Institute of Pakistan, International Islamic University, Islamabad since 2008 Previously she has headed various educational institutions both from school and college cadre.

She is supervising numbers of post graduates in their research thesis including M.Phil. and Ph.D. Thesis as well. Her area of interest is curriculum and science education. She is an author of various international publications and has presented at various forums also.

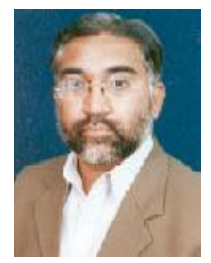

Hamid Hassan was born in Lahore the Capital of Punjab on April 16, 1967. He completed his Ph.D. in Education from the University of the Punjab, Lahore, Pakistan in 2007. Furthermore he did his Masters in Technology Education in 1995.

Currently, he is working as a lecturer in the Federal College of Education, Islamabad which is a post graduate teacher training institute catering the needs of both pre-service and In-service teachers' Education and training. He has received specialized trainings from Chiba University Japan, Plymouth University N.H. USA

$\mathrm{He}$ is supervising number of post graduate research students for their dissertations. His area of interest is curriculum, technical and vocational education, educational leadership and management. He is an author of various international publications. 